\title{
MAGNETIC RESONANCE IMAGING IN THE EVALUATION OF PATIENTS WITH ASEPTIC MENINGOENCEPHALITIS AND CONNECTIVE TISSUE DISORDERS
}

\author{
SIMONE APPENZELLER*, ELIANE KOBAYASHI**, LILIAN T.L. COSTALLAT***, \\ VERONICA DE ARAUJO ZANARDI***, JOSÉ MENEZES RIBEIRO NETO****, \\ BENITO PEREIRA DAMASCENO*****, FERNANDO CENDES *****
}

\begin{abstract}
Objective: To describe the role of magnetic resonance imaging (MRI) in the evaluation of patients with chronic and recurrent aseptic meningitis.Method: A retrospective study of five patients with aseptic meningoencefalitis diagnosed by clinical and CSF findings. CT scans showed without no relevant findings. Results: MRI showed small multifocal lesions hyperintense on T2 weighted images and FLAIR, with mild or no gadolinium enhancement, mainly in periventricular and subcortical regions. Meningoencephalitis preceded the diagnosis of the underlying disease in four patients (Behçet's disease or systemic lupus erythematosus). After the introduction of adequate treatment for the rheumatic disease, they did not present further symptoms of aseptic meningoencephalitis. Conclusion: Aseptic meningoencephalitis can be an early presentation of an autoimmune disease. It is important to emphasize the role of MRI in the diagnosis and follow-up of these patients.
\end{abstract}

KEY WORDS: magnetic resonance imaging, CNS vasculitis, aseptic meningitis, systemic lupus erythematosus, lupus, Behçet disease.

\section{Ressonância magnética na avaliação de pacientes com meningoencefalite asséptica e doenças do tecido conjuntivo}

RESUMO - Objetivo: Investigar a importância da ressonância magnética (RM) na avaliação de pacientes com meningite asséptica crônica ou recorrente. Método: Este é um estudo retrospectivo incluindo cinco pacientes com meningite asséptica crônica ou recorrente diagnosticada com base nos dados clínicos e exame do líquido cefalorraquidiano. Os exames de tomografia computadorizada de crânio não evidenciaram achados relevantes. Resultados: A RM mostrou pequenas lesões multifocais hiperintensas em T2 e FLAIR, com pouco ou nenhum realce após injeção de gadolínio, sobretudo nas regiões periventriculares e subcorticais. O quadro de meningoencefalite precedeu o diagnóstico da doença de base (Behçet ou lupus) em quatro pacientes. Após a introdução do tratamento adequado para a doença reumatológica estes pacientes não apresentaram mais sintomas de meningoencefalite. Conclusão: Meningite asséptica pode ser uma das manifestações precoces de doença autoimune. É importante salientar o papel da RM no diagnóstico e acompanhamento desses pacientes.

PALAVRAS-CHAVE: ressonância magnética, vasculite SNC, meningite asséptica, lupus eritematoso sistêmico, doença de Behçet.

Central Nervous System (CNS) involvement in autoimune connective tissue disease is a common feature, occurring in $20-75 \%$ of patients with systemic lupus erythematosus (SLE) ${ }^{1,2}$ and in $10-25 \%$ in Behçet disease ${ }^{3}$. Although any part of the CNS may be involved, one of the least common

Departamentos de Neurologia, Radiologia e de Reumatologia da Faculdade de Ciências Médicas (FCM) da Universidade Estadual de Campinas (UNICAMP): *Acadêmica de Medicina; **Médica Residente de Neurologia; ***Assistente do Departamento de Reumatologia; ****Assistente de Departamento de Radiologia; *****Assistente do Departamento de Neurologia. Aceite: 12-novembro-1999.

Dr. Fernando Cendes- Departamento de Neurologia, Faculdade de Ciências Médicas/UNICAMP - Caixa Postal 6111 - 13081-970 Campinas SP - Brasil. Fax 0192893801. 
manifestations is either acute or chronic aseptic meningitis or meningoencephalitis ${ }^{3}$. It may occur early in the course of the disease, and may be the initial presentation ${ }^{2}$, often delaying the diagnosis of the underlying disease. In contrast to aseptic meningitis, bacterial meningitis appears as a late complication in association with corticosteroid therapy ${ }^{3}$. The occurrence of aseptic meningitis or aseptic meningoencephalitis, as chronic or recurrent episodes, especially in young adults, should direct the investigation to chronic inflammatory diseases, specially SLE, Behçet disease and sarcoidosis $^{4}$, as to isolated viral meningitis, which is also common among young patients.

Involvement of the brain is a major cause of morbidity and mortality in patients with connective tissue disease, especially in SLE and Behçet disease. The treatment is hampered by the current lack of an accurate method of diagnosis and follow-up 5 . In addition to physical examination, cerebrospinal fluid (CSF) analysis, electroencephalogram and evoked-potential studies may all be useful, but not specific $^{5}$. Computerised tomography (CT) in most of the time fails in demonstrating the disease and the degree of brain involvement ${ }^{6}$. In fact, most frequently CT scans are normal or show mild cerebral atrophy. With advances in magnetic resonance imaging (MRI) techniques, the investigation became more sensitive, showing many lesions not seen on CT scans, suggestive of small vessel vasculitis, oedema, inflammatory and demyelinating lesions ${ }^{5,6}$.

We reviewed the clinical and MRI findings of five patients with chronic aseptic meningoencephalitis associated with SLE and Behçet disease in order to access the importance of MRI in evaluating these patients.

\section{METHOD}

The medical records of five patients with aseptic meningitis or aseptic meningoencephalitis with secondary CNS vasculitis followed in the Rheumatology and Neurology outpatient clinic were analysed retrospectively in relation to their clinical manifestations, CSF abnormalities, CT and MRI findings. Data were collected regarding the clinical presentation, neurological signs, and previous medical history. Blood and CSF examinations, CT and MRI scans were performed in all five patients.

MRI scans were obtained in a 2T scanner (Ellscint Prestige) with T1 - and T2-WI, as well as FLAIR, T1 inversion recovery and proton density axial scans and T1- and T2-WI sagittal scans, before and after gadolinium. Slices were six millimetres thick. Images acquisition parameters were as follows; T1 WI: repetition time (TR)= 550 , echo time (TE) $=10 \mathrm{~ms}$; matrix of $200 \times 270$ and field of view (FOV) of 180 X220 millimetres; T2 WI: TR= 4600, TE=128; matrix of 256 X 256 and FOV of 220 X220 millimetres; FLAIR: TR= 8500 and 2000 or 100 and $2200, \mathrm{TE}=72$ or 90 , matrix of $256 \mathrm{X} 296$ or $250 \mathrm{X} 256$ and FOV of $200 \mathrm{X} 220$ or 220 vs 220 millimetres; proton density: TR=4600, TE=16, matrix of 256 X 256 and FOV of 220 X 220 millimetres; T1- inversion recovery (IR): TR/TI $=1500 / 800$ or $2800 / 860, \mathrm{TE}=12$, matrix of $150 \mathrm{X} 256$ and FOV of $170 \mathrm{X} 200$ millimetres.

\section{RESULTS}

Patient 1. A 32-years-old woman first presented at 28-years-old with progressive left hemiparestesia, with onset 24 hours earlier and remission after 3 weeks. One week later, she developed occipital headache. Four weeks after that she reported blurred vision, visual impairment in the right eye and worsening of headache. As antecedents, she presented with erythema nodosum in lower extremities 9 months before and trombophlebitis four months before. Physical examination showed palsy of the right rectus lateralis and signs of papillitis. Laboratory exams showed high erythrocyte sedimentation rate (ESR), negative lupus erythematosus (LE) cells and antinuclear antibodies (ANA) preparations. Cranial CT was normal and CSF showed pleocytosis, increased proteins and increased IgG (Table 1). MRI scanning was not available at this time. During her admission to hospital she developed oral ulcers, which imprint demonstrated purulent inflammatory exudate. At this time the diagnosis of Behçet disease was made and corticosteroid and chloramphenicol were introduced. After loosing follow-up, she returned to our service four years later with the same initial symptoms starting two months before. In addition, she referred genital ulcers and during the physical examination it was noticed hypoestesia at the left hemibody (level at T7) and mild paresis in left lower extremity. ESR was elevated. CSF results are shown in Table 1. MRI three years after the initial symptoms showed small cortical and subcortical lesions hypointensive in $\mathrm{T} 1$ and hyperintensive in $\mathrm{T} 2$ with gadolinium enhancement, suggestive of small vessels vasculitis (Fig 1). 
Table 1. Cerebrospinal fluid analysis in patients with aseptic meningitis

\begin{tabular}{|c|c|c|c|c|c|c|}
\hline Date of CSF & $\begin{array}{l}\text { Cells/ } \\
\mathrm{mm}^{3}\end{array}$ & $\begin{array}{c}\text { Protein } \\
\mathrm{mg} / \mathrm{dl}\end{array}$ & $\begin{array}{c}\text { Glucose } \\
\mathrm{mg} / \mathrm{dl}\end{array}$ & $\begin{array}{l}\mathrm{IgG} \\
\mathrm{mg} / \mathrm{dl}\end{array}$ & $\begin{array}{l}\text { Oligoclonal } \\
\text { IgG bands }\end{array}$ & Culture \\
\hline \multicolumn{7}{|l|}{ Patient 1} \\
\hline 03/17/94 & 129 & 52 & 33 & 21.2 & NA & Negative \\
\hline $03 / 28 / 94$ & 84 & 62 & 49 & 20.7 & NA & Negative \\
\hline 08/02/94 & 31 & 38 & 58 & 7.01 & NA & Negative \\
\hline $11 / 03 / 97$ & 71 & 66 & 46 & 24.0 & Negative & Negative \\
\hline $11 / 20 / 97$ & 37 & 51 & 48 & 22.0 & Negative & Negative \\
\hline $01 / 26 / 98$ & 49 & 85 & 52 & 31.0 & 2 bands in gamma & Negative \\
\hline \multicolumn{7}{|l|}{ Patient 2} \\
\hline $11 / 23 / 91$ & 64 & 31 & 53 & NA & NA & Negative \\
\hline $11 / 21 / 91$ & 944 & 42 & 43 & NA & NA & Negative \\
\hline $12 / 04 / 91$ & 1.6 & 30 & 45 & NA & NA & Negative \\
\hline $02 / 26 / 92$ & 2.3 & 8 & 52 & NA & NA & Negative \\
\hline 03/10/98 & 165 & 282 & 29 & 3.93 & Negative & Negative \\
\hline 03/30/98 & 30 & 33 & 43 & NA & NA & Negative \\
\hline 07/29/98 & 1 & 30 & 64 & NA & NA & Negative \\
\hline \multicolumn{7}{|l|}{ Patient 3} \\
\hline $10 / 29 / 97$ & 204 & 74 & 76 & 8.0 & Negative & Negative \\
\hline $11 / 04 / 97$ & 100 & 99 & 63 & 8.0 & NA & Negative \\
\hline $12 / 28 / 97$ & 128 & 96 & 41 & 12.0 & Negative & Negative \\
\hline $01 / 14 / 98$ & 88 & 58 & 65 & NA & Negative & Negative \\
\hline 04/30/98 & 14 & 66 & 57 & NA & Negative & Negative \\
\hline \multicolumn{7}{|l|}{ Patient 4} \\
\hline 08/17/96 & 50 & 64 & 62 & NA & NA & Negative \\
\hline $05 / 22 / 97$ & 67 & 24 & 65 & 2.0 & NA & Negative \\
\hline \multicolumn{7}{|l|}{ Patient 5} \\
\hline 09/10/86 & 50 & 30 & 56 & NA & Negative & NA \\
\hline $12 / 18 / 86$ & 6 & 16 & 52 & NA & Negative & NA \\
\hline
\end{tabular}

NA, not availed.

Patient 2 - A 27-year old man first presented at 20 years old with blurred vision, fever and confusion. Physical examination stuffed neck and pyramidal signs. Laboratory data showed increased ESR and mucoproteins. CSF results are shown in Table 1. The diagnosis of viral meningitis was made and acyclovir was introduced. He presented clinical improvement and a new CSF examination was normal. Forty-five days later he presented with recurrent fever and headaches. CSF results are shown in Table 1. In the next three months he presented with erythema nodosum, oral and genital ulcers and deep venous thrombosis. The diagnosis of Behçet disease was made. At this time no MRI scans were available. Chlorambucil and colchicin were introduced, with partial improvement for 6 years. At this time he presented with fever, headache and gait abnormalities. In 24 hours he developed spinal cord syndrome with paraplegia and T6 sensitive level. CSF showed inflammatory characteristics 


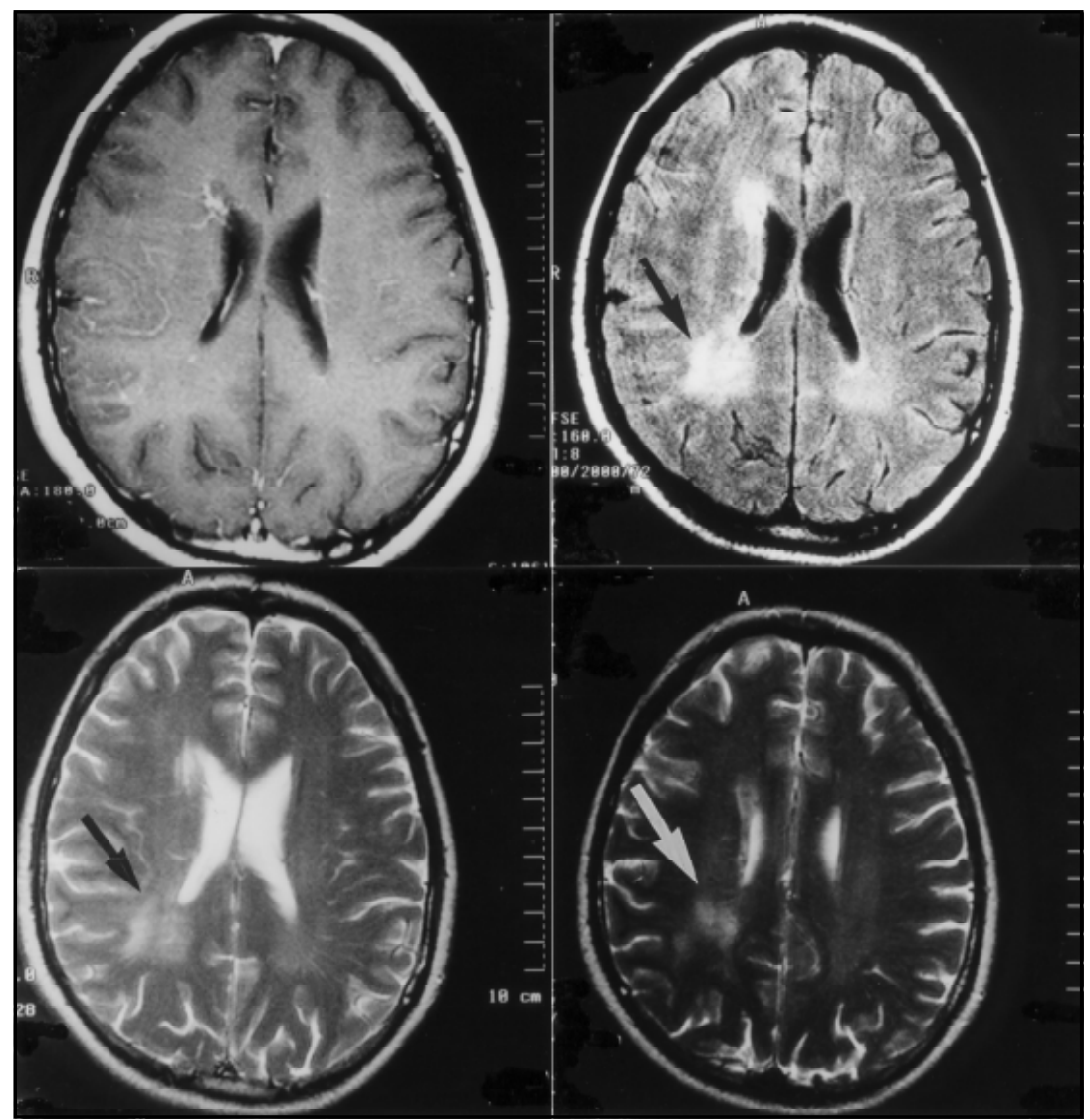

Fig 1. MRI from Patient 1: A) T1-weighted, B) FLAIR and C) and D) T2-weighted axial images showing diffuse periventricular lesions, hyperintense in T2- weighted and FLAIR and hypointense in $T 1$ with gadolinium enhancement. See methods for acquisition parameters.

(Table 1) and spinal CT was normal. MRI was not available at this time. He presented gait improvement after cyclophosphamide pulse therapy, and after one year of follow-up he still has urinary retention and mild paraparesis. Brain MRI showed vasculitis lesions (Fig 2) and spinal MRI at six months follow-up was normal.

Patient 3 - A 32-years old man presented in 1997 with ataxia, occipital headache with increasing intensity. One month later he presented with nausea and ataxia. Two months after that he referred blurred vision, and low-grade fever, aggressiveness and agitation. Physical examination showed fever, confusion, meningismus, papilledema and no focal signs. CT scan showed diffuse cerebral oedema. Because of signs of cranial hypertension CSF was obtained only 24 hours later. As the clinical presentation and CSF findings suggested aseptic meningitis, acyclovir and dexamethasone were introduced. After patient's clinical improvement, a new CSF examination showed inflammatory features (Table 1). Among the exams, we performed repeated inflammatory activity tests and we found positive LE cells, anti ENA and anti RNP antibodies. Antiphospholipine, ANA, anti DNA were negative. MRI showed diffuse periventricular and subcortical lesions hyperintense in T2WI and FLAIR and hypointense in T1WI with gadolinium enhancement (Fig 3). At this time the patient's diagnosis has not been definitively established, but SLE and Behçet disease have not been ruled out. He remains asymptomatic without medication. 


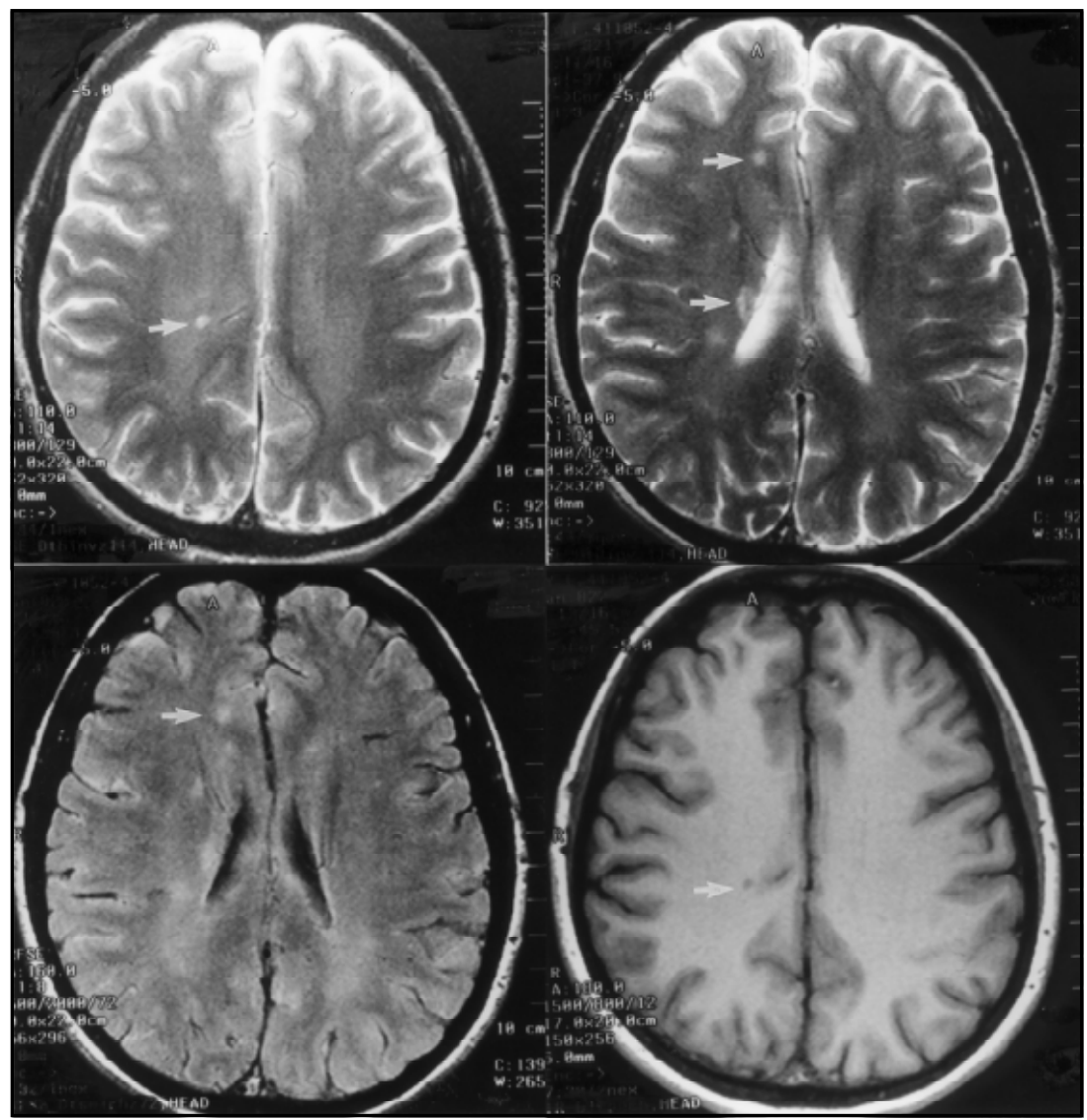

Fig 2. MRI from Patient 2: A) and B) T2-weighted, C) FLAIR and D) T1-IR images showing small subcortical periventricular lesions, hyperintense in T2 and FLAIR and hypointense in T1. No gadolinium enhancement was observed.

Patient 4 - A 36 year old woman presented in 1996 with frontal headache for two years with photophobia and vomiting. Additionally she had generalised tonic-clonic seizures and a CT scan showed intraparenchymatous calcification, suggesting sequel of neurocysticercosis, but with normal CSF examination and negative ELISA test for cysticercosis (Table 1). During follow-up visits, she referred genital and oral ulcers, arthralgia at knees and elbows one year before the presenting symptoms. At this time the diagnosis of Behçet disease was made and therapeutics with corticosteroid introduced. MRI scan two years after first symptoms showed multiple small lesions localized on subcortical region, mainly periventricular, basal ganglia and internal capsule, hypointense in $\mathrm{T} 1$ and hyperintense in $\mathrm{T} 2$, with no gadolinium enhancement.

Patient 5 - A 40-year-old woman presented in 1986 with poliarticular arthritis, erythema nodosum, oral and genital ulcers for eight years. One week before she referred difficulties to talk and swallow, blurred vision, inability to control vesical sphincter and Raynaud's phenomenon. Physical examination showed arthritis, joint effusion in the left knee, right hemiparestesia and hemiparesia, with pyramidal signs. Treatment with chlorambucil, colchicin and corticosteroid was introduced. During her admission to hospital she developed recent memory loss and confusion. CSF showed lymphocytosis (Table 1). ECG was normal. ANA were negative. The diagnosis of Behçet disease was made and the patient improved clinically after treatment. MRI scanning was not available at this time. After improvement, the patient lost follow-up and returned nine years later with arthritis 


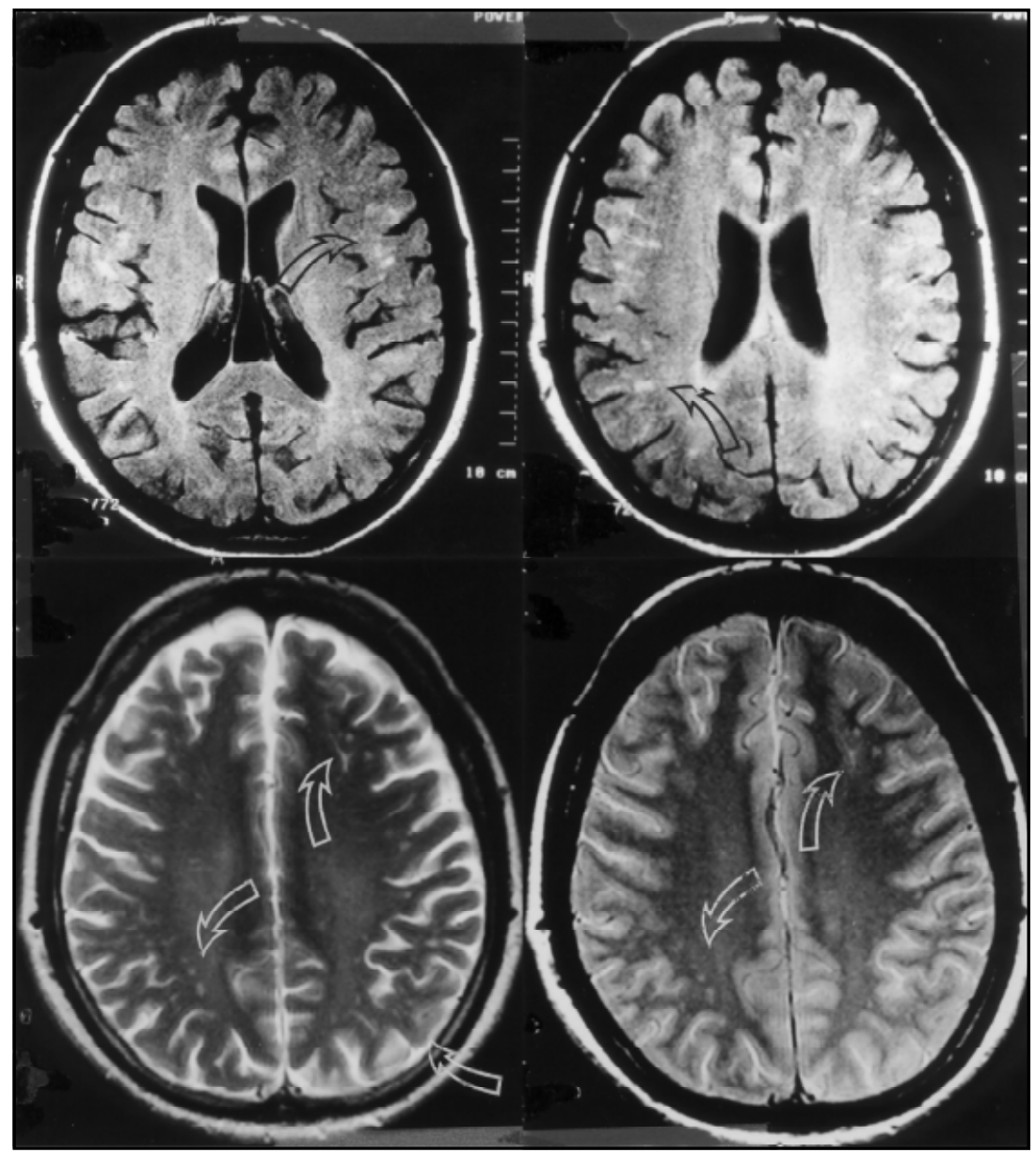

Fig 3. MRI from Patient 3: A) and B) FLAIR and C) and D) axial T2-weighted images showing multiple small subcortical and cortical lesions, hyperintense in T2, mainly in centrum ovale.

and genital ulcers. No neurological signs were seen during examinations. MRI showed diffuse periventricular and subcortical lesion hyperintensive in T2WI and hypointensive in T1WI without gadolinium enhancement suggesting demyelinating lesions secondary to vasculitis.

\section{DISCUSSION}

The determination of the cause of chronic or recurrent meningitis frequently remains a diagnostic dilemma, despite numerous technological advances. Aseptic meningitis or aseptic meningoencephalitis may be due to a variety of non-infectious processes, including chemical exposure, neoplasms, sarcoidosis, vasculitis and connective tissue disease. In these disorders, neurological involvement may be the presenting, dominant or sole manifestation? ${ }^{7}$.

SLE and Behçet disease are multisystemic autoimmune diseases of unclear pathogenesis. Neurological involvement in Behçet disease occurs in $10-25 \%{ }^{3}$ and is the presenting manifestation in up to $5 \%^{8}$. CNS involvement includes intracranial hypertension, dural sinus thrombosis, and intracranial lesions with predilection for deep structures and recurrent meningoencephalitis ${ }^{9}$. In SLE, neurological manifestation is even more common, occurring in $20-75 \%{ }^{1}$. 
Neuropathologic findings suggest that the lesions are primarily vascular with fibrinoid degeneration of collagen in small arteries and arterioles, leading to occlusion and ischemia. With the progression of the occlusive process, microinfartions develop, occasionally associated with haemorrhage and oedema. These are features that cannot be demonstrated by CT and are generally reversible with adequate treatment ${ }^{1,6,9}$.

In our patients, diagnosis of aseptic meningitis or aseptic meningoencephalitis were done based on CSF findings (Table 1). In four patients the clinical manifestation of aseptic meningitis or aseptic meningoencephalitis preceded the diagnosis of the underlying connective tissue disease and in one patient, it appeared eight years after the onset of symptoms. In three patients the diagnosis of Behçet disease was established and in the remaining two the definitive diagnosis is not yet established, but it is most likely to be either SLE or Behçet disease. After the introduction of adequate treatment for the underlying disease, the patients did not present another aseptic meningitis or aseptic meningoencephalitis.

MRI is helpful in the evaluation of patients with clinical evidence of CNS SLE and Behçet disease. In most patients MRI is abnormal, as reported in literature 9 . Lesions are more likely to occur in the brain stem, basal ganglia, thalamus and internal capsule. When compared to CT, MRI has been found to better delineate lesions seen on CT in addition to show lesions not usually seen on CT. In our study, lesions occurred more frequently in cortical and subcortical areas and CT was normal or showed only diffuse oedema. CT lesions in neuro-Behçet may reflect a reversible breakdown in the blood-brain barrier, possibly related to inflammation rather than gliosis or infarction?. On the other hand, the presence of focal findings on MRI implies true cerebral disease, which is an important point in differentiating drug effects or primary psychiatric illness ${ }^{9}$.

In all our patients, MRI showed small cortical and subcortical lesions hypointense in T1 and hyperintense in $\mathrm{T} 2$ with or without gadolinium enhancement suggestive of small vessels vasculitis. These features are not pathognomic for connective tissue disease, but they are not usually the kind of lesions found in aseptic meningoencephalitis due to other causes. Furthermore, these lesions, although non-specific, indicate brain involvement due to ischemic disorders secondary to vasculitis, and when associated with the clinical findings of chronic or recurrent aseptic meningitis or meningoencephalitis, strongly suggest an underlying connective tissue disease.

As aseptic meningitis or aseptic meningoencephalitis may be the first presenting symptom of connective tissue disease, these patients should be carefully evaluated and followed-up to determine other symptoms of connective tissue disease in order to establish the diagnosis and introduction of adequate treatment. Until this is made, aseptic meningitis and aseptic meningoencephalitis can recur. MRI is helpful in these cases, indicating brain involvement secondary to vasculitis and excluding lesions such as prominent meningeal enhancement, characteristic of bacterial meningitis.

\section{REFERENCES}

1. O'Conner P. Diagnosis of central nervous system lupus. An J Neurol Sci 1988;15:257-260.

2. Dubois L. Lupus erytematosus. 2Ed. Los Angeles: University of Southern California Press, 1974

3. Tervaert JWC, Kallenberg C. Neurologic manifestations of systemic vasculitides. Rheum Dis Clin N Am 1993;19:913-940.

4. Sands ML, Ryczak M, Broown RB. Recurrent aseptic meningitis followed by transverse myelitis as a presentation of systemic lupus erythematosus. J Rheumatol 1988;15;862-864

5. Aisen AM, Gabrielsen TO, Mc Cune WJ. MR imaging of systemic lupus erythematosus involving the brain. AJR 1985; 144:1027-1031.

6. Wechsler B, Dell'Isola B, Vidailhet M, et al. MRI in 31 patients with Behçet's disease and neurological involvement: prospective study with clinical correlation. J Neurol Neurosurg Psychiatry 1993;56:793-798

7. Cheng TM, O’Neil BP, Scheithauer BW, Piepgras DG. Chronic meningitis: the role of meningeal or cortical biopsy. Neurosurgery 1994;34:590-596

8. Nüssel F, Wegmüller H, Laseryas F, et al. Neuro-Behçet: acute and sequential aspects by MRI and MRS. Eur Neurol 1991;31:399-402

9. Patel DV, Neuman MJ, Hier DB. Reversibility of CT and MRI findings in neuro- Behçet disease. JCAT 1989;13:669-673. 